\title{
Kia whakatōmuri te haere whakamua: engaging Māori rural communities in health and social service care
}

AlterNative

$1-9$

(c) The Author(s) 2020

Article reuse guidelines:

sagepub.com/journals-permissions DOI: $10.1177 / 1$ I77/80120948275 journals.sagepub.com/home/aln (S)SAGE

\author{
Andre Mclachlan' (D), Suzanne Pitama² \\ and Simon Justin Adamson ${ }^{3}$
}

\begin{abstract}
Research on collaboration between health and social service organisations and professions often views collaboration from the narrow perspective of being between practitioners from different professions at a set point in time. This is often also focused on issues of efficacy and does not address the role of identity, values, and practices, or "culture" within collaboration, an important aspect when engaging with indigenous populations. This study presents a Kaupapa Māori qualitative case study in a small rural community, which highlights how western culture has permeated within and across a health care system. Recommendations are made to guide Crown and other western health and social service organisations and practitioners in first understanding the ongoing history of people and place, and its impact on health and social practice, and how to engage with Māori in a way that affirms, enables, and where requested supports a for Māori by Māori approach to wellbeing.
\end{abstract}

\section{Keywords}

culture, racism, Māori, Indigenous, rural, health

\section{Introduction}

The whakatauki (proverbial saying) "Kia whakatōmuri te haere whakamua" has been translated as "I walk backwards into the future with my eyes fixed on my past" (Rameka, 2006). This refers to the importance of knowing, acknowledging and building upon past knowledge and relationships to utilise the wisdom inherent within these for achieving Māori aspirations. This whakatauki will form the lens through which collaboration will be discussed in the introduction to this study.

As a term, "collaboration" is a rallying call and catchphrase used to encourage funded services in the health and social sectors to work together to produce synergistic outcomes. It is assumed that collaboration leads to better use of resources in a fiscally restrained environment and to better address complex, compounding and intergenerational health and social problems (Butterfoss, 2007; O'Leary, 2014; Taskforce on Whānau-Centred Initiatives, 2010). Despite the prominence of the term in government documents, the term collaboration is often not well defined (Harmsworth et al., 2016). A recent study identified that the term "collaboration" was defined less than $1 \%$ of the time in a wide range of New Zealand Government documents (located on the State Services Commission website) (O’Leary, 2014).

Collaboration within health and social service sector literature has been identified as systemic and interrelated, from the role of government, through to the interaction between service users and practitioners. Rose and Norwich (2014) proposed a framework of collaboration occurring on multiple levels and discussed the interaction between these levels. The framework includes four contexts in which collaboration occurs: policy context, local context, group functioning and individual factors. However, this model does not sufficiently account for the involvement of history, particularly the colonial footprint or culture and its impact on the framework. Martin-Rodriguez et al. (2005) identified important mechanisms within collaboration: interactional, organisational and systemic. The authors identified that cultural values "may also have an impact on the development of collaboration between professionals" and that "some cultures may harbour deep cultural values that run counter to the spirit of collaboration" (Martin-Rodriguez et al., 2005,

\footnotetext{
'Centre for Health and Social Practice, Waikato Institute of Technology, New Zealand

2 Māori Indigenous Health Institute, University of Otago, Christchurch, New Zealand

${ }^{3}$ National Addiction Centre, University of Otago, Christchurch, New Zealand
}

\section{Corresponding author:}

Andre Mclachlan, Centre for Health and Social Practice, Waikato Institute of Technology, Hamilton, Waikato 3200, New Zealand. Email: Andre.mclachlan@wintec.ac.nz 
p. 134). Despite culture being identified as one of the key systemic determinants of successful collaboration, culture was not incorporated within interactional or organisational elements. Hazel and Hawkeswood (2016) identify that culture could be considered to cover three different areas: organisational, ethnic, and project. They argue that "while the existence of differing ethnic cultures is at least on most people's radar (even if not always handled well), the intersection between organisational and project cultures is less visible" (Hazel \& Hawkeswood, 2016, p. 37).

"Whānau ora" (literally translated as "well families") is a New Zealand government health policy change in the last decade that has promoted both collaborative and culturally congruent models of health and practice for Māori and nonMāori. This policy change highlighted the importance of collaboration across sectors, between practitioners and with whānau (family) to meet the needs and aspirations of Māori. As a national health initiative, Whānau Ora guides policy and practice towards a more comprehensive and collaborative care for whānau (Taskforce on WhānauCentred Initiatives, 2010). The initial literature describing Whānau ora stated that "assurances will be required from a number of government departments and a spirit of collaboration must be embedded between funders, providers, practitioners and whānau" (Taskforce on Whānau-Centred Initiatives, 2010, p. 5).

An earlier pilot study conducted in another small rural community in the Waikato by McLachlan et al. (2012) identified specific cultural factors, including alcohol and drug services, that had implications for collaboration between Māori and non-Māori practitioners and services. The study identified that the cultural and geographic context, and history of a community, was important in providing culturally responsive services. The history of conflict between services was also identified as having a significant impact on ongoing collaborative efforts. A further finding explored that complexities of Māori practitioners working and living within their community, and navigating potential conflicts in holding dual roles.

Research exploring collaboration between mainstream and Aboriginal alcohol and drug services in Australia has also identified a wide range of systemic, inter-professional and cultural barriers to collaboration (Gray et al., 2014; Taylor et al., 2013). Systemic issues included underfunding indigenous services, and forcing collaboration with western mainstream services upon Aboriginal communitycontrolled alcohol and drug services. The Aboriginal health services identified that this type of coercive behaviour was reflective of intergenerational colonial practice "although mainstream partners were not directly responsible for the redirection of funding, by receiving it they were complicit in replicating a colonial practice that (once again) undermined Aboriginal self-control" (Taylor et al., 2013, p. 3). Western practitioners' lack of knowledge about Aboriginal preferences, abilities, practices, and values was identified as a creating barriers to effective collaboration between organisations, between western and indigenous practitioners, and between western practitioners and Aboriginal service users (Gray et al., 2014).
The purpose of this article is to present an example of how western identities, values, and practices - "culture" have permeated within a health care system across time, and across different levels of collaboration, from service design and funding, through to ongoing interactions between western practitioners and indigenous Māori practitioners and service users. Recommendations are made to guide Crown and other western health and social service organisations and practitioners in first understanding the ongoing history of people and place, and its impact on health and social practice, and how to engage with Māori in a way that affirms, enables, and where requested supports a for Māori by Māori approach to wellbeing.

\section{Methods}

This study was a Kaupapa Māori qualitative case study design. Thematic analysis was used for data analysis. See Figure 1 for an overview of the research methods. This study was approved by the University of Otago Human Ethics Committee. A whānau tautoko group was formed to represent local Māori researchers, iwi representatives, and representatives from Māori health and social service providers. This group provided guidance on local context issues and the application of locally congruent tikanga (cultural practices).

\section{Kaupapa Māori research}

Kaupapa Māori research (KMR) guides the researcher in ensuring that the objectives of research align with Māori aspirations, systemic post-colonial issues are explored, and the process of research is guided by local Māori, and their practices and preferences (Bishop, 1996; Moewaka-Barnes, 2000; Smith, 1999; Walker et al., 2006). Five Māori principles were established at the outset of the research, which guided both the design and analysis of data, as shown by the arrows between concepts in Figure 1. These five principles are well established within KMR theory and practice (Cram, 2001; Hudson et al., 2010; Jones et al., 2006; Smith, 1999).

\section{Case study design}

A case study strategy provides a conceptualisation of the area under study and incorporates different case study design elements. A "case" has been referred to as a "bound entity," usually in the form of a person, organisation, behavioural condition, or other social phenomena (Yin, 2012). This case study was undertaken within a large rural area of the North Island of New Zealand that contains several small rural communities. For the purposes of this research, the unit of analysis is collaboration, and the embedded units of analysis that are proposed to impact collaboration are also presented in Figure 1, these are Iwi, organisational development, and governmental policy histories; Māori service users and their whānau; practitioners and organisations; rurality and substance use and related problems. 


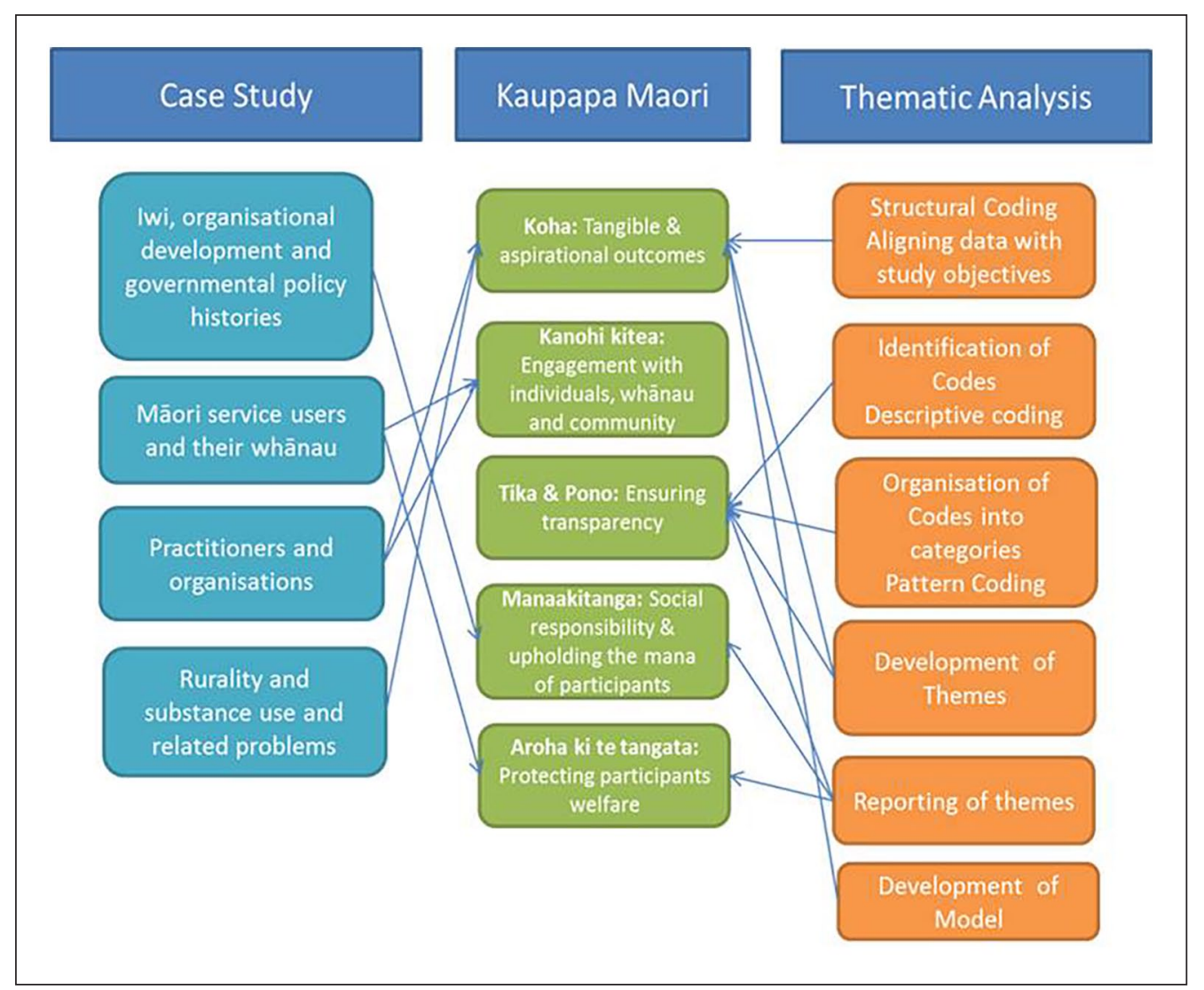

Figure I. Thematic analysis aligned with a Kaupapa Māori case study.

\section{Participants}

Three different stakeholder groups were selected to contribute to a multi-perspective view of collaboration. Individual interviews were conducted with key community members (KCM; $n=10)$. These participants were involved in the initial forming of services in the area and provided an understanding of collaboration across time; individual and group interviews were conducted with service users and their whānau (SU; $n=20)$. This involved service users with a self-identified substance use problem and engaging with two or more other health and social services and selfnominated whānau members. The final participant group involved three focus groups with health and social service practitioners (PFG; $n=21)$. These groups incorporated practitioners from a range of iwi (tribal), non-government community groups, and statutory services discussing their experiences of collaborating with service users and their whānau, and other practitioners, professions, and organisations.

\section{Data analysis}

The thematic analysis steps undertaken in this study are presented in Figure 1 and utilised the steps outlined by Braun and Clarke (2006) along with the three broad processes of thematic analysis described by Saldana (2013). The first step outlined in Figure 1 aligns with the first broad process described by Saldana (2013) "organisation of the data"; the next two align with the next process "data reduction"; and the final three steps align with "interpretive coding and the development of broader themes."

In the present study, each theme was labelled with a whakatauki, a Māori proverbial saying. Whakatauki has been cited as reflecting "valued characteristics, personal virtues, modes of behaviour, life lessons and appropriate courses of action" (Patterson, 1992 cited in Rameka, 2016, p. 394). For the present study, the use of these proverbial sayings to reflect the experiences of participants provides a direct connection to KMR methodology, that is, connecting with original knowledge and teachings.

\section{Results}

\section{Participants}

Of the three participants groups, all 10 community members (KCM) and the majority of the 22 service users and their whānau participants (SUW) identified as Māori, with links to the different Iwi within a large rural setting with the North island. These participants were able to provide information on service development and delivery over three to four decades. Fifteen of the 22 practitioner identified as Māori with links to the different Iwi within the area.

The majority of the KCM participants were either in the 46- to 55-year age bracket $(n=4)$ or $66+$ age bracket $(n=3)$. Four were male and six were female. The majority of the SUW participants were in the 18- to 25-year bracket $(n=7)$ and the 36 - to 45 -year bracket $(n=8)$. Nine were 
male and 13 were female. The majority of the practitioner participants were in the 36- to 65-year brackets (3650 years $=8,51-65$ years $=10)$. Twenty were female and two were male.

\section{Themes}

Three themes were identified which reflect the role of culture within collaboration and collective action. Culture is defined in this context as indigenous Māori identity, values, and practices. These were "Ahakoa kai tahi, tērā a roto te hahae kē rā: The ongoing impacts of colonisation on collaboration"; "Ko Apa whare rau: Understanding the history of people and place in creating collaborative relationships"; and "Whare tū ki te wā, he kai nā te ahi; whare tū ki roto ki te pā tūwatawata, he tohu nō te rangatira: Engaging with the fabric of the community to access naturally occurring systems of care".

Ahakoa kai tahi, tērā a roto te hahae kē rā: The ongoing impacts of colonisation on collaboration. Ahakoa kai tahi, tērā a roto te hahae kē rā ("although they share meals, within them is jealousy”) (Ihaka, 1958, in Mead \& Groove, 2001, p. 13). The proposed meaning was that true unity is more difficult to achieve than its appearance. Another way to translate the term hahae is to lacerate or harm. These translations allow for an acknowledgement and reflection of the difficulty of unity when harm has, or continues to take place.

This theme reflects the ongoing challenges and tensions in Māori-Crown collaboration relating to Māori aspirations for health and social services by Māori for Māori. This includes the systemic barriers to effective Māori representation and participation in health care design and delivery, and the different mechanisms the Crown uses to maintain the status quo that does not meet the needs or aspirations of Māori.

Several participants observed that the Crown and other non-Māori organisations often spoke about the importance of collaborating with Māori; however, this was seen by Māori as rhetoric, with no intention of these groups to follow-through and collaborate with Māori. This has contributed to some scepticism on the behalf of Māori when considering engaging in further collaboration with the Crown and other tau-iwi (non-Māori) groups:

Yeah. And I mean services, we always talk about, "Oh we've gotta have robust relationships," and "... we've gotta work in collaboration." It's like, yeah it's all lip service ... there was no action. It was a Pākehā [non-māori] organization said it out front but there was no action and no changing of infrastructure that allowed that to happen. (KCM9)

The lack of confidence in collaborating with Crown representatives was evident in participants' reports that collaboration with the Crown did not necessarily transfer into commitment from the Crown to constructively work with Māori, or that there would be any beneficial outcomes for Māori:

This person said to me that collaboration was a tau iwi word that meant that "we may or may not work with you." (KCM9)
It was noted that Māori often sit on Crown and other tauiwi boards to represent the interest of specific Māori groups, often the sole Māori representative on a large board, which led them to feel isolated and overlooked. In turn, they found they were unable to actively engage in the collaborative process. These boards were noted to gain access to the broader Māori networks that these participants represent. When boards do not follow through with collaboration, the Māori representative is implicated in this failure and is left feeling unsafe and used:

So I became a thorn in their side and said to them, "Well no, kei te he tena [that is not correct]. You know, if you're gonna say something to my people, you need to follow it; you need to follow it through because I'm not going to allow you to takahia [trample on] on the networks that I have or the hononga [connections/relationships] that I have with my whānau around this motu[land], around this rohe [area]; so that you can get some runs on the board, kao [no]; yeah sorry." (KCM 9).

It was also observed by participants that District Health Boards (DHBs) had a lack of knowledge of Māori health needs and how to work with Māori, and if Māori were not present at higher levels of planning and decision-making that Māori views would neither be tabled nor addressed:

And I mean the only reason why, I always make sure I try and get to it . . . if her and I don't talk about the inequalities and how they're supposed to be addressing them. They just swan straight over the top of it. (KCM2)

Participants described that when entering into collaborative relationships with the Crown, there was a perception from Crown representatives that the Crown was the authority on what was needed for Māori:

She essentially said to us, who did we think we were challenging the DHB, who were doing great work for Māori people. She was quite derogatory in the way she spoke to us. (KCM 10)

Alongside this use of power, Crown health contracts were aligned with Crown imperatives, and these did not often align with Māori needs, paradigms, or preferences. Participants expressed a desire for Māori organisations to engage in more research and development in relation to Māori needs and preferences. Participants noted that Crown health paradigms produced funding contracts that focused on specific national health targets, which did not necessarily align with the needs of the local community. The fundamental differences in health philosophies between Māori and tau-iwi (non-Māori settlers) were identified by the majority of participants as contributing to tension:

I don't see our health and our social and our cultural and economic as separate things. I see them as encapsulated in everything that we do. It doesn't matter what it is, that we have to have an understanding of how that all fits together. And how that strengthens us and helps us to grow. (KCM10)

Participants also commented that iwi organisations were not able to meet the aspirations of delivering services to 
their own people who may live outside of the contracted geographical boundaries:

It has been frustrating that most of our population is elsewhere and yet our contracts are confined to this geographic area that's our rohe. There's a disconnect there. (KCM5)

Several participants identified that Māori practitioners and services were viewed by others, as of lower quality than other mainstream services. This included practitioners, services, and, at times, service users and their whānau. Participants noted that mainstream services also received better funding and community and business sponsorship, which reinforced these perspectives:

Well there is second best and not - if you're not European — if you're Māori you're seen as lesser than European or Pākehā. That's still quite-you get that a lot, like even within services that if it's a Māori service it's not as good as the-like isn't as good as [national provider delivering service locally] and yet they do the same thing. Sure, when I came out here. Oh yeah, when I came out here. When I was mental health in town and I hadn't come across that negativity towards to Māori providers and when I came out here there was very much you're the second cousins, you're the poor bro. (PFG2)

The majority of participants also reported that mainstream practitioners, particularly specialist health practitioners, devalued Māori health and social service practitioners. Participants recognised that mainstream practitioners questioned their qualifications and professionalism, and that this was a barrier to the establishment of collaborative relationships, as they did not get treated as collaborative partners:

To them, we're just the Māori taxi service. What do you do? And we've tried and tried and tried to build that relationship. (PFG3)

Several service users and their whānau reported that attitudes displayed by practitioners through their behaviour had a direct impact on the service user and whānau willingness to engage in and maintain involvement within a collaborative relationship. Several participants reported experiencing racism and other forms of discrimination, which reduced their willingness to engage in collaboration. They reported that often services and practitioners did not care about their needs or did not provide access to service options or entitlements due to their culture, substance use history, or affiliations with gangs:

You should be able to walk into any department, regardless of colour and creed, feel relaxed enough to be able to sit there without a thought of, "Is this person going to sit in judgment on me?," "Is this person going to support me in what I need, in the right way or is this person going to say, "Well, you don't qualify for that." (SU2)

Several participants described examples where the practitioners they were engaging with were unable to meet their cultural needs, and at times appeared unwilling to do so. This lack of cultural competence led whānau to disengage from services:

When I went through mental health for my daughter in 2005, we actually weren't given, I felt, the services that we needed and one of them was that when we took our daughter, we weren't allowed to have karakia[traditional prayer]. . . . I actually don't know. I'm not sure whether it was the Pākehā nurse or whether it was the doctor.. It upset my girl. It also upset me and I ended the meeting there .... The first visit we had, he wasn't there. It was just me and my daughter. When we asked if we could have a prayer to start, the doctor got up, he walked out and the nurse followed him and then she was sent back in while me and my daughter we left sitting in the room and she came back in and said that no, that it would be preferred that they just do the diagnosing. I said no 'cause my daughter was still in that unstable state and she had a reaction to that so we had to leave anyway. (SU 2)

Ko Apa whare rau: Understanding the history of people and place in creating collaborative relationships. Ko Apa whare rau ("Apa of many houses") (Grey, 1853, p. 89, in Mead \& Groove, 2001, p. 225). From a superficial level, this whakatauki can reflect the many homes and whānau across the region. However, this whakatauki is also used to reflect the many stories of the whakapapa (genealogical relationships or historical relationships) and migration of the Iwi. Therefore, this whakatauki reflects a theme of communities and the multiple realities of Māori and nonMāori within these communities.

This theme reflects the role of historical connections and tensions within and between different Māori stakeholder groups seeking to engage in collaboration and collective action. Participants identified that there were often tensions between expectations and aspirations of each stakeholder group. Addressing these internal hapū (sub-tribes), iwi and Māori provider tensions were identified as vital for Māori in order for Māori to develop strong coherent collaborative strength when engaging in collective action, and in collaboration with external groups such as Crown funders and other providers. Understanding Māori preferences and processes for collaboration and collective action may also provide guidance for non-Māori in engaging with Iwi and other Māori organisations.

Participants commented that a key challenge to collaboration between those in service delivery and whānau service users arose when historical conflict between their respective whānau, hapū, or iwi had occurred. This led to mistrust and at times personal conflict that affected the service delivery relationship:

Yeah. You know, you try doing that 15 years ago, woulda been downright dangerous 'cause, you know, half a chance is, "Oh your tupuna [ancestor] ripped us off. You guys can piss off back where you came from." That's the kind of thing that happened; I've seen it happen with my own eyes. (KCM5)

Participants identified whakapapa and land as important enablers of collaborative relationships between peoples and groups. Whakapapa was seen as a strong bond that implied a natural connection between people and groups, and a 
history of living and working in the community was identified as an important connector between peoples and groups. Participants observed that whakapapa to waka (traditional migrating canoes) provided historical bonds that allowed iwi groups to come together based on shared history. This was seen as a starting point for acknowledging connection between groups that may have historically fought with each other, and more recently competed for national and regional social, health, and education contracts:

\section{... that's that whole business that they chose to put it together like this because of our whakapapa links with each other and the waka thing; Aotea, Tokomaru, Kurahaupo Waka for the region you know, still working with that kind of linking. (KCM 6)}

Participants commented that often having knowledge of one's whakapapa allowed key stakeholders to make personal connection with other key stakeholders. Whakapapa also allowed for key stakeholders to be seen in a positive light, particularly if the key stakeholder had leadership whakapapa. Participants noted that key stakeholders would often cite their whakapapa, and their knowledge of others' whakapapa to build relationships and resolve conflicts. This process reflects the values and principles of Māori, the importance and acknowledgement of whakapapa, and the respect held for the deeds and standing of past leaders.

Participants identified shared history, experience, and connection to the land and other geographical features such as maunga (mountains) and awa (rivers) as a further representation of whakapapa, which enabled collaboration. These factors provided a central shared history that allowed for a common anchor to collaboration:

You see, so knowing some of the history behind how groupings happen and as each merge is .... The [river] is a big binder of all of. If we might get a little bit tight about things, we know that the [river] is swallowed by [two other rivers across the region], the greatest thing for [hapū (sub-tribe)] I tell you. Fly the [river] flag and that's Pākehā and Māori alike. So if you're talking relationships, even to the Pākehā communities now, it's about that; who are we and where's our identity in the [river]? (KCM 6)

Participants mentioned that non-Māori with a strong family connection to the region or with a personal history of working and living in the area was respected as a connection to the land and commitment to the community. This was seen as an important enabler of collaborative relationships, as key stakeholders with a personal connection to the area were seen as having a personal connection and commitment to what was important to local people:

We moved back and his family were highly regarded and still are there, so because I married into his whānau, then I must have been okay .... And so that gave me a foot in door to anywhere really — and still does .... It is the insider type thing. (KCM1)
Whare tū ki te wā, he kai nā te ahi; whare tū ki roto ki te pā tūwatawata, he tohu nō te rangatira: Engaging with the fabric of the community to access naturally occurring systems of care. Whare tū ki te wā, he kai nā te ahi; whare tū ki roto ki te pā tūwatawata, he tohu nō te rangatira ("A house that stands in open country is susceptible to loss by fire, while one that stands within a fence pa is the mark of a distinguished person") (Williams, 1908, in Mead \& Groove, 2001, p. 425). This whakatauki identifies the importance of whānau being together for wellbeing and to face challenges. This whakatauki also reflects the challenge of isolation faced by some service users who may have moved away from whānau, or who may be disconnected from whānau due to the impact of whānau or service users substance use and associated mental health and social problems. This theme builds upon the previous theme of understanding the context and historical relationships between groups, by identifying the importance of actively and consistently engaging with the wider fabric of the service users, their whānau, hapū, and Iwi.

Health and social service practitioners noted that whānau and communities hold unique strengths, resources, and skills. Participants identified that these collective abilities were in some ways a first-line response to growing health and social problems and were often able to identify and respond to health and social issues quicker than health and social service organisations.

Several participants reported that the culture of the whānau they worked with was an important aspect that influenced collaboration. Participants identified the importance of understanding and engaging with Māori, and building upon this relationship in linking service users and their whānau with other practitioners and services:

It's easier to work with a Pākehā. It is. But it's hard working with Māori because you have to understand how they work, how they think. And then you become the bridge between them and the services and while you're being a bridge you're actually building strong relationships with this-you know, with the other side, which is really cool. (PFG3)

Participants reported that to mobilise community strengths, skills, and resources, practitioners need to also be aware of community leaders, groups, cultures, and organisations. Participants acknowledged that better awareness of these resources led to local solutions. This was seen as a key enabler of rural collaborative practice:

You have really got to know your community for one thing; you need to know what's going on. It's not all the vulnerable things that are going on, all the issues that are going on; you need to know who potentially - they may not even be working in the health or social service area-within that community you can bring on board to be part of your collaboration? I guess that's the beauty of a smaller community because you do get to know your community really quickly and who you can rely on and who you can't. (PFG1)

The majority of participants noted the importance of practitioners having a good understanding of the community 
fabric, that is, the history, preferences, relationships, leaders, and groups within the community. Participants observed that by understanding the communities within an area, the practitioner is better able to access and work with local resources. This is seen by participants as a significant enabler of collaborative practice in rural communities:

I think isolation to start with. We're not like in a big city where you've got all the services there and you can just ring up. You haven't got that here. So sometimes I think when you're isolated you've got to know your community well and therefore then you'll be able to plug into different ones that are around. But you've got to be known in the community as well. (PFG2)

The majority of participants reported that community meetings, described as either hui (meeting) or forums, were a vital aspect of initiating collective action and maintaining collaborative relationships. Participants noted that by bringing together practitioners in general meetings, even if service users were not being discussed at the meeting, they could still access practitioners after the meeting. This kanohiki-te-kanohi (face-to-face) contact enabled relationship strengthening and allowed practitioners to update each other on practice issues related to their shared work, particularly between local providers and in-reach providers from urban centres:

They've all got something in common. I love the meeting. I can't miss it because the value that we get from that for this handful or whatever that we're working with is phenomenal. So it's like after that meeting, right, I need to talk to you, you and you, and so going around face to face is just so awesome. (PFG2)

Kanohi-ki-te-kanohi (face to face) and kanohi kitea (the seen face) were phrases used by several participants to reflect the importance of being actively engaged within the community. To be seen and to be known. Being seen and engaged in the community was seen as an important step is the sharing aspect of collaboration, as opposed to just taking from a collaborative relationship:

You just have to be involved whether it's at the Kōhanga [Children's Māori language learning centre], at the kindergarten, at the school sports is another one. Connect to the networks. For experience. Physical presence is huge. You have just got to rump on up. You don't just take; you have got to give back as well. It's the whole sharing; so you have got to have that relationship as well and knowing what can you contribute before you can ask them of something. That's really important and I think that sets the whole foundation of building that relationship in the beginning. (PFG 1)

Participants recognised the importance of consistent engagement between practitioners, and practitioners following through with their commitments as key aspects of maintaining collaborative relationships:

So if you haven't been out there and done the hard yards yourself and actually established some relationships that can be a real barrier and of course follow up when you are engaging with the agency and making sure you stay true to your word; that can be a barrier if you don't follow up what you say you are going to do. We're the same in [town]; we're working with an agency in [nearby town] and if we don't keep that communication going with them that can be a real barrier for us. (PFG 1)

\section{Discussion}

The introduction to this article outlined the growing concern that models of collaboration within health and social service sectors did not acknowledge or incorporate the needs, practices, or preferences of indigenous peoples. This lack of acknowledgement was argued to lead to poor outcomes and poor engagement in collaboration between parties, from service design and funding, through to service delivery. This study sought to better understand Maori experiences and perspectives across this spectrum of collaboration.

This study found that systematic racism continues to undermine the development of Māori organisations and reduce the effectiveness of Crown and other western organisations collaborating with Māori organisations; this was cited by participants to be an impact of colonisation. This systemic racism was evident within Crown contracting for services that were defined by western geographical boundaries, western priorities, and the valuing and promotion of western models of practice and western organisations. Māori experiences of working with Crown and other western representatives and organisations were reflective of paternalistic unequal power relationships, with Māori participating in collaborative processes becoming isolated, overworked, and undervalued, and often urban "in reach" services showing a lack of commitment.

The downstream impacts of this systemic racism included direct discrimination towards Māori practitioners and organisations, who were often seen as a "taxi service" as opposed to practitioners and experts in their fields. This racism was also reported by Māori service users who identified being discriminated against, and not having their cultural needs met within engagement with western practitioners.

In response to the systemic nature of racism across all levels of health and social practice, participants identified the importance of practitioners, organisations, and the Crown having a historical and ongoing understanding of the peoples and places where they engage. Whakapapa was noted to be a binding force for Māori, including multiple "anchors" or pathways such as waka, geography, and within and between whānau, hapū, and iwi. It was also noted to be vital for addressing common goals, vision and for addressing conflicts within Māori collaborative relationships. Participants also identified the desire for a bottom-up approach to health and social service care, where the community was the provider, and funding enabled communities to respond to community's needs. This was seen as an important enabler of a for Māori by Māori approach. To work more effectively with Māori, the Crown 
and other western health and social service practices were expected to engage in a consistent and meaningful way with the community, as opposed to infrequently applying specialist clinical services in an ad hoc way. This approach did not build foundational elements for collaboration, such as familiarity and trust.

The experience of systemic racism is best captured within the WAI2575 inquiry into health services and outcomes for Māori (Waitangi Tribunal, 2019). Within this report, the crown acknowledged that racism is present in the health sector and is affecting Māori health. The small number of published studies that discuss collaboration between Crown and iwi health and social services acknowledge that collaborative processes are often driven by government timeframes and priorities, which have led to insufficient time and attention to relationships or joint negotiation (McKenzie et al., 2008). Racism towards service users has been identified within the literature as barriers to collaboration (Jansen et al., 2009; Rameka, 2006). This racism was identified as contributing to poor health outcomes including mental health and substance use problems (Marrone, 2007). The importance of whakapapa, the rituals associated, and its value in developing relationships with others is evident in national literature (McLachlan et al., 2012; Ministry of Education, 2009; O'Leary, 2014), and also in the study by Taylor et al. (2013) on Aboriginal Australians experiences of collaborative relationships between indigenous and government services. The importance of cultural competencies within working with service users and their whānau are evident within the literature reviewed (Chin et al., 2018; Gray et al., 2014; Marrone, 2007; Taylor et al., 2013). However, there is little in the way of explicit crossover of cultural competencies in literature regarding collaboration between different organisations, professions, or practitioners. There was some discussion regarding addressing cultural competencies with non-indigenous practitioners through training (Gibsin et al., 2015; Taylor et al., 2013).

This study's strengths included participation by KCM and service users; however, a limitation of the present study was the absence of primary health care general practitioners involved in participant focus groups. There was also a limited number of male participants across all three participant groups.

\section{Conclusion}

To increase the safety and protect the mana of Māori participating in collaboration with the Crown and other western organisations, it is important that Iwi and Māori organisations develop representation strategies to ensure Māori representation and reduce the isolation of Māori participating in collaborative processes. To address systemic racism across all levels of collaboration, it is important that the Crown and other western organisations take a different approach to engagement, one built over time, based on a shared understanding of whakapapa between people, place, and the presenting issues. This requires a look beyond just the cultural competencies of a practitioner, or the Crown and other western organisations participating in a generalised workshop on The Treaty of Waitangi (The English version of the treaty between Māori and non-Māori).

Addressing barriers to effective collaboration with Māori also requires a layer deeper than co-development models of collaboration and collective action. This requires a historical and contextual understanding and meaningful engagement with the local people. Kanohi kitea is an important Māori value, which could be applied to strengthening western practitioners and organisations connection with the community, not only to increase familiarity and trust through communication, but the organisations and practitioners understanding and locating the values, strength, and resources of and within these communities.

It is also important that the Crown, organisations, and professions understand their ongoing impact on the community and its peoples. This is important for addressing paternalistic western practices and barriers to iwi and Māori organisations engaging in collective action with Crown and other western organisations. This is also important to address paternalism, racism, discrimination, and the resulting stigma that reduces Māori engagement and retention in health and social services. To address the colonial footprints in our communities, the Crown and other western organisations must create well-worn relational footprints and mobilise our naturally occurring systems of care - whānau hapū and iwi.

\section{Declaration of conflicting interests}

The author(s) declared no potential conflicts of interest with respect to the research, authorship, and/or publication of this article.

\section{Funding}

The authors disclosed receipt of the following financial support for the research, authorship, and/or publication of this article: The primary author received a Health Research Council Māori Health PhD Scholarship.

\section{ORCID iD}

Andre Mclachlan (DD https://orcid.org/0000-0001-7348-2467

$\begin{array}{ll}\text { Glossary } & \\ \text { Awa } & \text { rivers } \\ \text { Hapū } & \text { sub-tribes } \\ \text { Hui } & \text { meeting } \\ \text { Iwi } & \text { tribe } \\ \text { Kanohi kitea } & \text { the seen face } \\ \text { Kanohi-ki-te-kanohi } & \text { face to face } \\ \text { Maunga } & \text { mountain } \\ \text { Pākeha } & \text { non-Māori } \\ \text { Tau-iwi } & \text { non-Māori settlers } \\ \text { Te Tiriti o Waitangi } & \text { The Te Reo Māori version of the Treaty } \\ & \text { of Waitangi } \\ \text { Tikanga } & \text { Cultural practices } \\ \text { Waka } & \text { traditional migrating canoes } \\ \text { Whakapapa } & \text { genealogical relationships or historical } \\ & \text { relationships } \\ \text { Whakatauki } & \text { proverbial saying }\end{array}$


Whānau

Whānau ora

family

well families

\section{References}

Bishop, R. (1996). Whakawhānaungatanga: Collaborative research stories. Dunmore Press.

Braun, V., \& Clarke, V. (2006). Using thematic analysis in psychology. Qualitative Research in Psychology, 3, 77-101.

Butterfoss, F. (2007). Coalitions and partnerships in community health. Jossey-Bass.

Chin, M. H., King, P. T., Jones, R. G., Jones, B., Ameratunga, S. N., Muramatsu, N., \& Derrett, S. (2018). Lessons for achieving health equity comparing Aotearoa/New Zealand and the United States. Health Policy, 122(8), 837-853.

Cram, F. (2001). Rangahau Maori: Tona tika, tona pono-The validity and integrity of Maori research. In M. Tolich (Ed.), Research ethics in Aotearoa New Zealand (pp. 35-52). Reed Publishing.

Gibsin, O., Lisy, K., Davy, C., Aromataris, E., Kite, E., Lockwood, C., ... Brown, A. (2015). Enablers and barriers to the implementation of primary health care interventions for indigenous people with chronic diseases: A systematic review. Implementation Science, 10(71), 1-11.

Gray, D., Wilson, M., Allsop, S., Saggers, S., Wilkes, E., \& Ober, C. (2014). Barriers and enablers to the provision of alcohol treatment among Aboriginal Australian: A thematic review of five research projects. Drug and Alcohol Review, 33(5), 482-490.

Harmsworth, G., Awatere, S., \& Robb, M. (2016). Indigenous Māori values and perspectives to inform freshwater management in Aotearoa-New Zealand. Ecology and Society, 21(4), 9.

Hazel, J., \& Hawkeswood, J. (2016). Barriers to collaboration within the community service sector: An exploration. The Incubate Group.

Hudson, M., Milne, M., Reynolds, P., Russell, K., \& Smith, B. (2010). Te Ara Tika. Guidelines for Māori research ethics: A framework for researchers and ethics committee members. Health Research Council of New Zealand.

Jansen, P., Bacal, K., \& Crengle, S. (2009). He Ritenga Whakaaro: Māori experiences of health services. Mauri Ora Associates.

Jones, R., Crengle, S., \& McCreanor, T. (2006). How Tikanga guides and protects the research process: Insights from the Hauora Tane Project. New Zealand Journal of Social Policy, $29,60-77$.

Marrone, S. (2007). Understanding barriers to health care: A review of disparities in health care services among indigenous populations. International Journal or Circumpolar Health, 66(3), 188-198.

Martin-Rodriguez, L., Beaulieu, M., D’Amour, D., \& FerradaVidela, M. (2005). The determinants of successful collaboration: A review of theoretical and empirical studies. Journal of Interprofessional Care, 19(1), 132-147.

McKenzie, D., Whiu, T. A., Matahaere-Atariki, D., Goldsmith, K., \& Kōkiri, T. P. (2008). Co-production in a Māori context. Social Policy Journal of New Zealand, 33, 32-46.

McLachlan, A., Hungerford, R., Schroder, R., \& Adamson, S. (2012). Practitioners' experiences of collaboration, working with and for rural Maori. The Australian Community Psychologist, 24(1), 52-63.

Mead, H., \& Groove, N. (2001). Ngā pepeha a ngā tīpuna: The sayings of the ancestors. Victoria University Press.

Ministry of Education. (2009). Te Aho Arataki Marau - Kura Auraki mō te Ako i Te Reo Māori: Curriculum guidelines for teaching and learning Te Reo Māori in English-medium schools: Years 1-13. Learning Media Limited.

Moewaka-Barnes, H. (2000). Kaupapa Maori: Explaining the ordinary. Pacific Health Dialog, 7(1), 13-16.

O'Leary, R. (2014). Collaborative governance in New Zealand: Important choices ahead. Fulbright New Zealand.

Rameka, R. (2006). He arakanihi ki te oranga: Report of Health Research Council, Rangahau Hauora award. Te Rōpū Rangahau Hauora a Eru Pōmare.

Rameka, L. (2016). Kia whakatōmuri te haere whakamua: 'I walk backwards into the future with my eyes fixed on my past'. Contemporary Issues in Early Childhood, 17(4), 387-398.

Rose, J., \& Norwich, B. (2014). Collective commitment and collective efficacy: A theoretical model for understanding the motivational dynamics of dilemma resolution in interprofessional work. Cambridge Journal of Education, 44(1), $59-74$.

Saldana, J. (2013). The coding manual for qualitative researchers (2nd ed.). SAGE.

Smith, L. (1999). Decolonising methodologies. University of Otago Press.

Taskforce on Whānau-Centred Initiatives. (2010). Whānau Ora: Report of the taskforce on Whānau-centred initiatives.

Taylor, K., Bessarab, D., Hunter, L., \& Thompson, S. (2013). Aboriginal-mainstream partnerships: Exploring the challenges and enhancers of a collaborative service arrangement for Aboriginal clients with substance use issues. BMC Health Services Research, 13, Article 12.

Waitangi Tribunal. (2019). WAI 2575: Hauora report on stage one of the health services and outcomes Kaupapa inquiry. https://forms.justice.govt.nz/search/Documents/WT/wt_ DOC_152801817/Hauora\%20W.pdf

Walker, S., Eketone, A., \& Gibbs, A. (2006). An exploration of Kaupapa Maori research, its principles, processes and applications. International Journal of Social Research Methodology, 9(4), 331-344.

Yin, R. K. (2012). Applications of case study research (3rd ed.). SAGE. 